\title{
Lysine Metabolism in Mammals
}

\author{
By FLORENCE C. I. FELLOWS* and MAXWELL H. R. LEWIS \\ Departments of Child Health and Biochemistry, \\ The Queen's University of Belfast, Belfast, U.K.
}

(Received 9 April 1973)

\begin{abstract}
The enzymes involved in the initial degradative steps of lysine metabolism, lysine2-oxoglutarate reductase and saccharopine dehydrogenase, were studied and their activities in different mammals compared. Values obtained in human, rat, pig, dog, cat, ox and sheep liver indicated that in vitro, appreciable degradation of lysine to saccharopine (4-6 nmol/min per $\mathrm{mg}$ of protein) occurred. The specific activity of saccharopine dehydrogenase in most species studied was higher than that of lysine-oxoglutarate reductase. The rate of production of glutamate from saccharopine in each animal species was investigated and related to the rate of production of $\alpha$-aminoadipate. The rate of formation of lysine from saccharopine, catalysed by saccharopine oxidoreductase, was examined and correlated with the dietary intake of lysine in each species studied.
\end{abstract}

Higashino et al. (1965) suggested that saccharopine may be a key intermediate in the degradative pathway of lysine in rats. They demonstrated that isolated rat liver mitochondria convert L-lysine into saccharopine in the presence of $\alpha$-oxoglutarate. Grove \& Henderson (1968) were unable to confirm the role of saccharopine in L-lysine degradation in vivo in rats or to establish an alternative pathway. However, they observed the removal of the $\alpha$-amino group from $D$-lysine to form pipecolic acid, thereby indicating the presence of two distinct pathways for lysine degradation.

Studies of hereditary metabolic disorders of lysine have contributed greatly to the elucidation of its degradative pathways. Hutzler \& Dancis (1968) investigated the initial degradative step of lysine in humans. They demonstrated that an enzyme, lysine2-oxoglutarate reductase, was able to catalyse conversion of lysine and $\alpha$-oxoglutarate into saccharopine in vitro. Further studies on patients with hyperlysinaemia (Dancis et al., 1969) confirmed that these patients have a deficiency of lysine-2-oxoglutarate reductase. These studies have thus established the important role of lysine-2-oxoglutarate reductase and saccharopine in the degradation of lysine in humans.

The presence of saccharopine in human physiological fluids was first reported by Carson et al. (1968) who described a case of saccharopinuria. Later studies (Fellows, 1972) revealed that this metabolic disorder is caused by the absence of an enzyme, saccharopine dehydrogenase, which converts saccharopine into $\alpha$-aminoadipate $\delta$-semialdehyde and glutamate. From further studies of the metabolism of saccharopine on ox and human liver, Fellows (1972) and Wang \& Lewis (1972) reported the

* Née Wang. identification of an enzyme, saccharopine oxidoreductase, which catalyses the hydrolysis of saccharopine to lysine and $\alpha$-oxoglutarate.

The object of the present work was to establish and relate the activities of lysine-oxoglutarate reductase, saccharopine dehydrogenase and saccharopine oxidoreductase in different mammals.

\section{Experimental}

\section{Materials}

Human livers were obtained, with permission of the Belfast City Hospital, at autopsies from cases of accidental death of previously healthy individuals or from patients who died of diseases that did not impair liver function. Rat (Wistar strain), dog (mongrels) and cat (tabby) livers were obtained from the respective healthy adult animals. Ox, pig and sheep livers were collected at the local abattoir immediately after slaughter and transported to the laboratory in ice.

$\alpha-\left[5-{ }^{14} \mathrm{C}\right]$ Oxoglutarate was obtained from The Radiochemical Centre, Amersham, Bucks., U.K. $\mathrm{L}$-[lysyl-U-14 $\mathrm{C}]$ Saccharopine and $\mathrm{L}$-saccharopine were prepared by the methods of Fellows (1973).

\section{Methods}

Desalting technique. Cation-exchange column chromatography was used for desalting the incubation media and amino acid fractions as described by Fellows (1973).

Two-dimensional chromatography and high-voltage electrophoresis. Amino acids were separated and identified as described by Fellows (1973).

Preparation of [glutamyl-14 C] saccharopine. This was synthesized enzymically with a partially purified 
lysine-2-oxoglutarate reductase prepared from ox liver by the method of Hutzler \& Dancis (1968). The incubation medium contained: $\alpha-\left[5-{ }^{14} \mathrm{C}\right]$ oxoglutarate $(50 \mu \mathrm{Ci}) ; \alpha$-oxoglutarate $(2 \mu \mathrm{mol})$; NADPH $(4 \mu \mathrm{mol})$; potassium phosphate buffer, pH7.0 (50 $\mu \mathrm{mol})$; enzyme extract (1 $\mathrm{mg}$ of protein) and water to a final volume of $1 \mathrm{ml}$. The incubation was for $90 \mathrm{~min}$ at $30^{\circ} \mathrm{C}$ and under a constant flow of $\mathrm{N}_{2}$. The reaction was terminated by the addition of sulphosalicylic acid $(50 \mathrm{mg})$, which precipitated the protein. The supernatant was subjected to a Technicon amino acid autoanalyser (the buffer gradient used was that of Wang \& Carson, 1968) to separate [ glutamyl $1{ }^{14} \mathrm{C}$ ]saccharopine, which was collected by a BTL fraction collector. This fraction was desalted on a column $(1 \mathrm{~cm} \times 5 \mathrm{~cm})$ of Dowex $50 \mathrm{~W}(\mathrm{X} 8)$. The column was first washed with deionized water $(500 \mathrm{ml})$ and then eluted with $2 \mathrm{M}-\mathrm{NH}_{3}$. The eluate was dried and redissolved in water. The product, [ glutamyl $-{ }^{14} \mathrm{C}$ ]saccharopine, was homogeneous on both highvoltage electrophoresis and two-dimensional chromatography. The total yield was $30 \mu \mathrm{Ci}$.

Isolation of mitochondria. All procedures were carried out at temperatures between $0-4^{\circ} \mathrm{C}$.

The liver was cut into small fragments with scissors and rinsed a few times with cold buffered sucrose solution [sucrose (0.25 $)$; Tris- $\mathrm{HCl}, \mathrm{pH} 7.4(5.0 \mathrm{mM})$; EDTA (1 mM)] to remove any contaminating blood. The chopped livers were minced in an Ato-Mix laboratory blender (MSE) with $5 \mathrm{vol}$. of buffered sucrose solution for $30 \mathrm{~s}$. The latter was further homogenized in a Potter-Elvehjem homogenizer by five passes of the Teflon pestle. The homogenate was centrifuged at $700 \mathrm{~g}$ for $10 \mathrm{~min}$ in an $8 \times 50 \mathrm{ml}$ fixed angle rotor of an MSE High-Speed 18 centrifuge. The supernatant was decanted into clean pre-cooled tubes and centrifuged at $9000 \mathrm{~g}$ for $7 \mathrm{~min}$. This second supernatant was discarded and the pellets were twice resuspended and re-centrifuged at $9000 \mathrm{~g}$ for $7 \mathrm{~min}$. Finally, the pellets were resuspended in the buffered sucrose solution (one-tenth of the volume of original homogenate).

Protein determination. Protein was measured by the method of Lowry et al. (1951), A calibration curve was prepared from bovine serum albumin.

Enzyme assays. Lysine-2-oxoglutarate reductase was assayed by the method described by Fellows (1973).

Saccharopine dehydrogenase was assayed under conditions modified from those described by Hutzler \& Dancis (1970). The incubation medium contained in $0.5 \mathrm{ml}$ : L-saccharopine $(1.0 \mu \mathrm{mol}) ; \mathrm{L}-$ - glutamyl$\left.{ }^{14} \mathrm{C}\right]$ saccharopine $(0.2 \mu \mathrm{Ci})$; $\mathrm{NAD}^{+}(2.0 \mu \mathrm{mol})$; Tris$\mathrm{HCl}$ buffer, pH8.8 $(50.0 \mu \mathrm{mol})$, and enzyme extract (1 mg of protein). Incubation was for $90 \mathrm{~min}$ at $30^{\circ} \mathrm{C}$. The reaction was terminated by the addition of sulphosalicylic acid $(50 \mathrm{mg})$ and the precipitated protein was removed by centrifugation. Glutamate
$(1.0 \mu \mathrm{mol})$ was added to the supernatant as carrier. The medium was desalted and the $\left[5-{ }^{14} \mathrm{C}\right]$ glutamate formed from $\mathrm{L}$-[ glutamyl $\left.-{ }^{14} \mathrm{C}\right]$ saccharopine was separated by high-voltage electrophoresis. The radioactivity of $\left[5-{ }^{14} \mathrm{C}\right]$ glutamate was determined by liquid-scintillation counting.

Enzymic degradation of saccharopine to a-aminoadipate. The incubation medium contained in $0.5 \mathrm{ml}$ : L-saccharopine $(1.0 \mu \mathrm{mol})$; L-[lysyl-U- $\left.{ }^{14} \mathrm{C}\right]$ saccharopine $(0.2 \mu \mathrm{Ci})$; $\mathrm{NAD}^{+}(2.0 \mu \mathrm{mol})$; Tris- $\mathrm{HCl}$ buffer, pH9.0 $(50.0 \mu \mathrm{mol})$; enzyme extract $(1 \mathrm{mg}$ of protein). Incubation was for $90 \mathrm{~min}$ at $30^{\circ} \mathrm{C}$ and the reaction was terminated by the addition of sulphosalicylic acid $(50 \mathrm{mg})$. To the supernatant $\alpha$-aminoadipate $(1.0 \mu \mathrm{mol})$ was added as carrier. $\alpha-\left[\mathrm{U}-{ }^{14} \mathrm{C}\right]$ Aminoadipate formed from $\mathrm{L}-\left[\right.$ lysyl-U- $\left.{ }^{14} \mathrm{C}\right]$ saccharopine was separated by high-voltage electrophoresis and the radioactivity was determined by liquid-scintillation counting.

Saccharopine oxidoreductase. The incubation medium contained in $0.5 \mathrm{ml}$ : L-saccharopine $(1.0 \mu \mathrm{mol}) ; \quad$ L-[lysyl-U- $\left.{ }^{14} \mathrm{C}\right]$ saccharopine $(0.2 \mu \mathrm{Ci})$; $\mathrm{NADP}^{+}(2.0 \mu \mathrm{mol}) ; \mathrm{NH}_{4} \mathrm{Cl}(40.0 \mu \mathrm{mol}) ;$ Tris $-\mathrm{HCl}$ buffer, pH9.2 $(50.0 \mu \mathrm{mol})$ and enzyme extract $(1 \mathrm{mg}$ of protein). Incubation was for $1 \mathrm{~h}$ at $30^{\circ} \mathrm{C}$ and the reaction was terminated by the addition of sulphosalicylic acid $(50 \mathrm{mg})$. L-Lysine $(1.0 \mu \mathrm{mol})$ was added to the medium as carrier. $\mathrm{L}-\left[\mathrm{U}-{ }^{14} \mathrm{C}\right]$ Lysine formed from $\mathrm{L}-\left[\right.$ lysyl-U- $\left.{ }^{14} \mathrm{C}\right]$ saccharopine was analysed by high-voltage electrophoresis and the radioactivity determined by liquid-scintillation counting.

Liquid-scintillation counting. The amino acid spots were cut out from paper and shaken in $2 \mathrm{ml}$ of aq. $50 \%$ methanol at room temperature for $4 \mathrm{~h}$, then $15 \mathrm{ml}$ of Bray's (1960) scintillation fluid was added to the extract and counted in a Packard Tri-Carb liquid-scintillation counter after $4 \mathrm{~h}$ of equilibrium in the counting chamber.

Quench correction was made by the method of Bell (1968) by using an automatic external standard.

\section{Results and Discussion}

The present findings suggest that, in the mammalian species studied, saccharopine is a key intermediate (Scheme 1) in the degradative pathway of lysine metabolism. The activity of lysine-2-oxoglutarate reductase (Table 1) is readily detected in all the species studied, the highest specific activity being recorded in the pig and sheep, the lowest in the dog. Values obtained in human and rat liver indicate that appreciable degradation of lysine to saccharopine occurs in vitro in these species. A small amount of free saccharopine has been found in normal mouse liver (Higashino et al., 1971). Saccharopine has not, however, been detected in the physiological fluids of normal humans (Carson, 1969) nor in the urine of rats after injection 


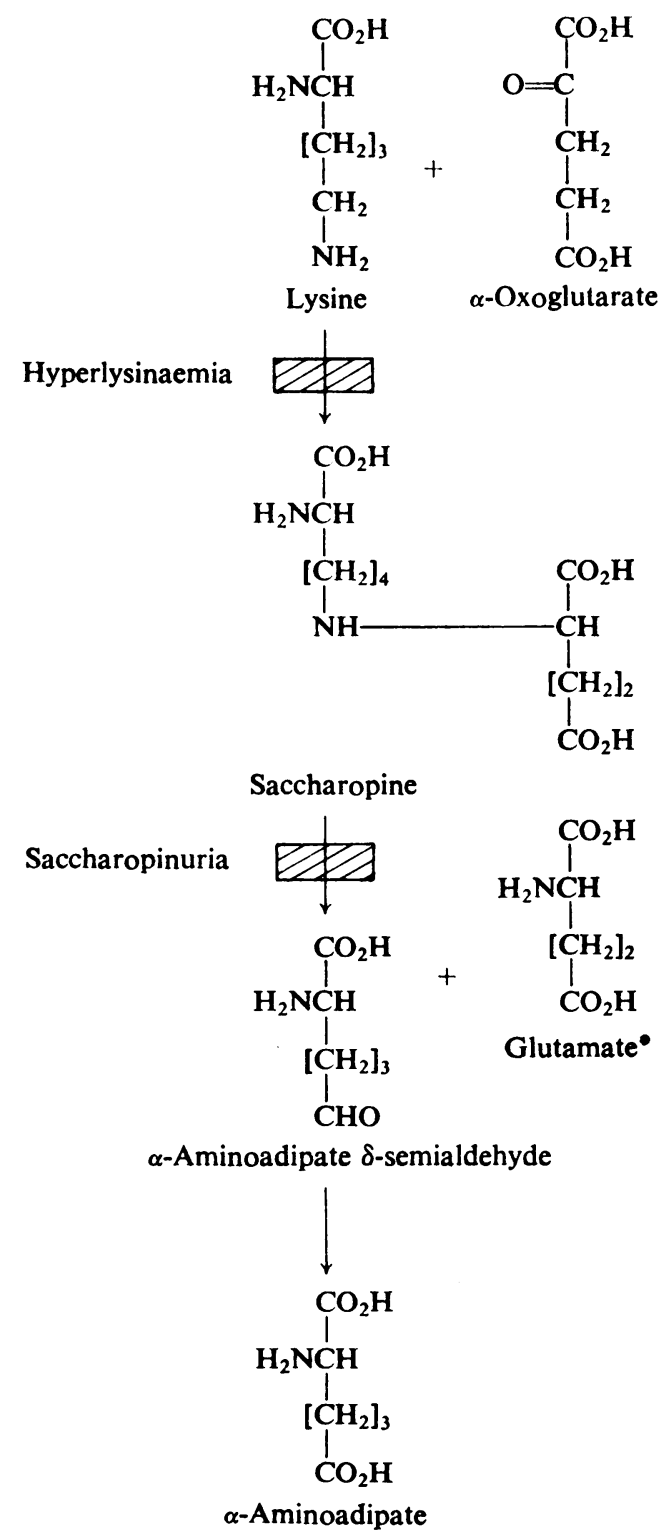

Scheme 1. The major pathway of lysine degradation in mammals and the specific genetic blocks in the pathway

a, Known genetic blocks.

of $\left[{ }^{14} \mathrm{C}\right]$ lysine (Grove \& Henderson, 1968). However, saccharopine, which is formed in vivo exclusively from lysine and $\alpha$-oxoglutarate, may be rapidly degraded to glutamate and $\alpha$-aminoadipate $\delta$-semialdehyde. Therefore under normal physiological conditions saccharopine may have a high rate of turn-
Table 1. Lysine-oxoglutarate reductase activity in liver mitochondria of various mammals

Incubation conditions were as recorded in 'Methods'. Enzyme activity was estimated by calculation of the radioactivity of $\left[\right.$ lysyl-U- $\left.{ }^{14} \mathrm{C}\right]$ saccharopine formed from $\left[\mathrm{U}-{ }^{14} \mathrm{C}\right]$ lysine. The results recorded were those obtained from three or more animals of each species.

Lysine-oxoglutarate reductase activity (pmol of saccharopine formed/min per mg of protein)

\begin{tabular}{lcc}
\cline { 2 - 2 } \multicolumn{1}{c}{ Source } & Range & Mean \\
Human & $3700-4900$ & 4425 \\
Rat & $4170-5600$ & 4770 \\
Pig & $4830-6300$ & 5400 \\
Dog & $3170-3900$ & 3500 \\
Cat & $3600-5100$ & 4230 \\
Ox & $3950-5570$ & 4500 \\
Sheep & $4270-6100$ & 5330 \\
& & \\
\hline
\end{tabular}

Table 2. Saccharopine dehydrogenase activity in liver mitochondria

Incubation conditions were as recorded in 'Methods'. Enzyme activity was measured by calculation of the radioactivity of $\left[5-{ }^{14} \mathrm{C}\right]$ glutamate formed from [glutamyl $\left.-{ }^{14} \mathrm{C}\right]$ saccharopine. The results recorded were those obtained from three or more animals of each species.

$\begin{array}{lcc}\text { Source } & \begin{array}{c}\text { Raccharopine dehydrogenase activity } \\ \text { (pmol of glutamate formed/min } \\ \text { per mg of protein) }\end{array} \\ \text { Human } & 3230-5860 & \text { Mean } \\ \text { Rat } & 4850-5400 & 4695 \\ \text { Pig } & 5530-6083 & 5030 \\ \text { Dog } & 5180-6330 & 5820 \\ \text { Cat } & 6040-8500 & 5500 \\ \text { Ox } & 4300-4690 & 6900 \\ \text { Sheep } & 5100-5730 & 4510 \\ & & 5430\end{array}$

over in these animals and consequently does not accumulate in the tissues or body fluids. This possibility is indicated by the findings (Table 2) on the activity of saccharopine dehydrogenase which, in each species studied, is $0-37 \%$ higher than that of lysine-2-oxoglutarate reductase. These two enzymes presumably act sequentially in vivo. Therefore any saccharopine formed from lysine would rapidly be converted into $\alpha$-aminoadipate $\delta$-semialdehyde and 
glutamate. Saccharopine dehydrogenase activity is readily detected by estimation of $\left[5-{ }^{14} \mathrm{C}\right]$ glutamate formed from [ glutamyl ${ }^{14} \mathrm{C}$ ] saccharopine. The direct estimation of $\alpha$-aminoadipate $\delta$-semialdehyde proved to be unsatisfactory. This failure to detect the second product of saccharopine dehydrogenase activity may result from the rapid oxidation of $\alpha$-aminoadipate $\delta$-semialdehyde to $\alpha$-aminoadipate in vitro. Thus incubation of $\left[l y s y l-\mathrm{U}-{ }^{14} \mathrm{C}\right]$ saccharopine with liver mitochondria resulted in the production of nonradioactive glutamate and one radioactive product that was identified as $\alpha$-aminoadipate. The relative rates of production of $\alpha$-aminoadipate from [lysyl$\left.\mathrm{U}-{ }^{14} \mathrm{C}\right]$ saccharopine in the various species are recorded in Table 3. For each mammal studied they are lower than the respective value recorded (Table 2) for saccharopine dehydrogenase. Although NAD ${ }^{+}$ was found to be an essential cofactor for saccharopine dehydrogenase in each species, no additional cofactor was required for the oxidation of saccharopine to $\alpha$-aminoadipate. The number of steps involved in the degradation of saccharopine to $\alpha$-aminoadipate is therefore uncertain, although the specific activities recorded in Tables 2 and 3 indicate that at least two steps are involved.

Paik et al. (1957) observed that $\epsilon-N$-acetyl-lysine can replace lysine for growing rats and maintain a growth rate close to that produced by the equivalent amount of L-lysine. This observation was supported by the discovery of an enzyme, $\epsilon$-lysine acylase, in rat tissues, which catalyses the hydrolysis of $\epsilon-N$-acetyllysine to lysine at a high rate. This is the only reported evidence that lysine is substituted by an amino acid

Table 3. Degradation of saccharopine to $\alpha$-aminoadipate by liver mitochondria of various mammals

Incubation conditions were as recorded in 'Methods'. Enzyme activity was measured by calculation of the radioactivity of $\alpha$-[U- $\left.{ }^{14} \mathrm{C}\right]$ aminoadipate formed from $\left[\right.$ lysyl-U- $\left.{ }^{14} \mathrm{C}\right]$ saccharopine. The results recorded were those obtained from investigations of three or more animals in each species.

Saccharopine degradation (pmol of $\alpha$-aminoadipate formed/ min per mg of protein)

$\begin{array}{lcc}\text { Source } & \text { Range } & \text { Mean } \\ \text { Human } & 3500-4950 & 4300 \\ \text { Rat } & 4570-5450 & 4780 \\ \text { Pig } & 4750-5800 & 5160 \\ \text { Dog } & 4250-5470 & 4850 \\ \text { Cat } & 5210-7500 & 5950 \\ \text { Ox } & 3750-4270 & 3900 \\ \text { Sheep } & 4500-5100 & 4790\end{array}$

which supports the growth of rats. Wang \& Lewis (1972) reported that lysine can be synthesized from saccharopine in vitro. The enzyme involved, saccharopine oxidoreductase, was studied in various mammals and the results are recorded in Table 4 . The highest specific activity was found in the livers of ox and sheep; that in human liver was considerably lower, being only $17 \%$ of that found in ox liver, and the mean values obtained for the dog and cat were the lowest. These results suggest that all mammals so far studied have the ability, in vitro, to synthesize lysine from saccharopine as precursor. The variation of the rate of lysine synthesis in these mammals may be interpreted to suggest that saccharopine oxidoreductase activity is correlated with the protein content of the animal's diet. Thus carnivorous animals, such as dogs and cats, receive adequate amounts of dietary lysine and consequently have a very low activity of saccharopine oxidoreductase. In contrast, herbivorous animals, such as ox and sheep, are fed on a diet containing a relatively low concentration of lysine, and consequently a high enzyme activity. An omnivorous diet, such as that of normal humans or rats, results in a relatively low saccharopine oxidoreductase activity.

The specific activity of saccharopine oxidoreductase in pig's liver (Table 4) is considerably higher than that of other omnivores and lower than that of the herbivores. This intermediate enzyme activity is possibly a reflexion of the animal's adaptation to a wide range of dietary intake.

The activity of saccharopine oxidoreductase in vitro

\section{Table 4. Saccharopine oxidoreductase activity in liver} mitochondria of various mammals

Incubation conditions were as recorded in 'Methods', except that instead of $40 \mu \mathrm{mol}$ of $\mathrm{NH}_{4} \mathrm{Cl}, 25 \mu \mathrm{mol}$ was used in incubations of human, rat, dog and cat liver. Enzyme activity was measured by calculation of the radioactivity of $\left[\mathrm{U}-{ }^{14} \mathrm{C}\right]$ lysine formed from [lysyl$\left.\mathrm{U}-{ }^{14} \mathrm{C}\right]$ saccharopine. The results recorded were those obtained from three or more animals of each species.

Saccharopine oxidoreductase activity (pmol of lysine formed/min per $\mathrm{mg}$ of protein)

\begin{tabular}{lcc}
\cline { 2 - 3 } \multicolumn{1}{c}{ Source } & Range & Mean \\
Human & $157-185$ & 165 \\
Rat & $125-201$ & 155 \\
Pig & $410-640$ & 563 \\
Dog & $94-126$ & 105 \\
Cat & $55-79$ & 67 \\
Ox & $700-1350$ & 950 \\
Sheep & $610-850$ & 780
\end{tabular}


Table 5. Liver capacity of lysine formation and degradation in various mammals

The assay conditions for each enzyme were as recorded in 'Methods'. Whole liver homogenates were used as enzyme sources. Enzyme activities were measured by calculations of the radioactive products formed from their substrates. The results recorded were the mean values obtained from three or more animals of each species.

$\begin{array}{lccc}\text { Source } & \begin{array}{c}\text { Lysine } \\ \text { (g formed/whole } \\ \text { liver per 24h) }\end{array} & \begin{array}{c}\text { Lysine } \\ \text { (g degraded/whole } \\ \text { liver per 24h) }\end{array} & \begin{array}{c}\text { Saccharopine } \\ \text { (g degraded/whole } \\ \text { liver per 24h) }\end{array} \\ \text { Human } & 1.780 & 41.39 & 114.46 \\ \text { Rat } & 0.002 & 0.10 & 0.20 \\ \text { Pig } & 1.430 & 18.94 & 38.95 \\ \text { Dog } & 0.068 & 4.07 & 12.72 \\ \text { Cat } & 0.015 & 1.89 & 5.56 \\ \text { Ox } & 13.030 & 63.58 & 131.16 \\ \text { Sheep } & 1.990 & 16.80 & 32.39\end{array}$

is not affected in the presence of exogenous lysine in the incubation mixture. Examination of both ox and human liver mitochondria revealed that the enzyme activity was not inhibited by the end-product, lysine, even at a concentration tenfold greater than that of the substrate.

From these initial studies it is suggested that the activity of saccharopine oxidoreductase in different mammals may be subject to genetic variation, and the mechanism of control may be repressed or induced by the intake of dietary lysine.

In studies on the amino acid requirements of man, Rose and his co-workers (Rose et al., 1955) determined the minimum lysine intake per day to be $0.8 \mathrm{~g}$. From the present results on lysine formation from saccharopine in vitro (Table 5) it may be concluded that human liver may adequately meet this requirement. The rate of lysine formation in vivo would, however, be considerably lower since saccharopine does not normally accumulate. Lysine production in the rat (Table 5 ) is about $12 \%$ of the daily minimum requirement $(16 \mathrm{mg})$ reported by Neuberger \& Webster (1945). This is in contrast with our findings in the human, but when daily requirement of lysine is correlated with body weight, it appears that the rat (Neuberger \& Webster, 1945) is considerably more dependent on dietary lysine than is the human (Rose, 1949). In the ruminant, micro-organisms probably have some effect on amino acid requirements although the significance of the high "saccharopine oxidoreductase activity in ox liver (Table 5) may be a requirement for a more balanced supply of amino acids.

In contrast with the relative activity of saccharopine oxidoreductase in various mammals, the activities of lysine degradative enzymes (Tables 1,2 and 3 ) do not appear to be correlated with the animal's diet. The activities of lysine-2-oxoglutarate reductase and saccharopine dehydrogenase in mammalian livers in vitro (Table 5), show that there is ample reserve of these two enzymes for the degradation of normal dietary lysine. In the human, for example, the liver alone has a capacity to metabolize about $40 \mathrm{~g}$ of lysine into saccharopine per day. Similarly, the conversion of saccharopine into $\alpha$-aminoadipate $\delta$-semialdehyde and glutamate by saccharopine dehydrogenase shows (Table 5) that human liver has a capacity to degrade $114 \mathrm{~g}$ of saccharopine per day. If it is assumed that the results obtained from these studies in vitro reflect the capacity of the system in vivo, then the enzymes of mammalian liver should adequately metabolize the normal intake of dietary lysine. Also, since lysine is an essential amino acid for mammals, most of the ingested lysine would be used for the maintenance of $\mathbf{N}$ equilibrium and replacement of tissue protein. The free lysine present in the body fluid would be limited. Under usual physiological conditions, it is unlikely that hyperlysinaemia or saccharopinuria would occur.

\section{References}

Bell, T. K. (1968) Lab. Pract. 17, 809-812

Bray, G. A. (1960) Anal. Biochem. 1, 279-285

Carson, N. A. J. (1969) Proc. Symp. Soc. Study Inborn Errors Metab. 6th, 163-171

Carson, N. A. J., Scally, B. G., Neill, D. W. \& Carré, I. J. (1968) Nature (London) 218, 679

Dancis, J., Hutzler, J., Cox, R. P. \& Woody, N. C. (1969) J. Clin. Invest. 48, 1447-1452

Fellows, F. C. I. (1972) Ph.D. Thesis, The Queen's University of Belfast

Fellows, F. C. I. (1973) Biochem. J. 136, 321-327

Grove, J. A. \& Henderson, L. M. (1968) Biochim. Biophys. Acta 165, 113-120

Higashino, K., Tsukada, K. \& Lieberman, I. (1965) Biochem. Biophys. Res. Commun. 20, 285-290

Higashino, K., Fujioka, M. \& Yamamura, Y. (1971) Arch. Biochem. Biophys. 142, 606-614

Hutzler, J. \& Dancis, J. (1968) Biochim. Biophys. Acta 158, 62-69 
Hutzler, J. \& Dancis, J. (1970) Biochim. Biophys. Acta 206, 205-214

Lowry, O. H., Rosebrough, N. J., Farr, A. L. \& Randall, R. J. (1951) J. Biol. Chem. 193, 265-275

Neuberger, A. \& Webster, T. A. (1945) Biochem. J. 39, 200-202

Paik, W. K., Bloch-Frankenthal, L., Birnbaum, S. M., Winitz, M. \& Greenstein, J. P. (1957) Arch. Biochem. Biophys. 69, 56-66
Rose, W. C. (1949) Fed. Proc. Fed. Amer. Soc. Exp. Biol. $8,546-552$

Rose, W. C., Wixom, R. L., Lockhart, H. B. \& Lambert, G. F. (1955) J. Biol. Chem. 217, 987-995

Wang, F. C. I. \& Carson, N. A. J. (1968) Colloq. Amino Acid Anal. 6th, Technicon Monograph 3, 118-126

Wang, F. C. I. \& Lewis, M. H. R. (1972) Biochem. J. 130, 74P-75P 